\title{
OPQPp/\% ( Psychiatry \\ PREVALENCE OF OBSESSIVE COMPULSIVE SYMPTOMS IN PSYCHIATRIC DISORDERS: A CROSS SECTIONAL STUDY
}

Dr Hiral Kotadia*

Assistant professor, Department of psychiatry, Sri Aurobindo Institute of Medical Sciences, Indore, $453555 .{ }^{*}$ Corresponding Author

\section{Dr Gupta Priyanka Attending consultant, Medanta - The Medicity hospital, Gurugram}

ABSTRACT Background : Obsessive compulsive symptoms (OCS) have known to co-occur with various psychiatric disorders and Knowing the prevalence of OCS in different psychiatric disorders can give a better understanding about the illness and help in shaping its management. This study aims at finding prevalence, types \& severity of OCS in patients presenting with different psychiatric disorders in Psychiatry Out patient department at a tertiary care institute.

Methodology : A total of 380 patients were included in the. Clinical diagnosis of obsessions \& compulsions was made as per criteria in Diagnostic \& Statistical Manual for Mental Disorders Fourth Edition, Text Revision (DSM IV- TR). Yale brown Obsessive Compulsive Scale (YBOCS) was applied for assessing severity of obsessive compulsive symptoms.

Results \& Conclusion: Prevalence of OCs in Psychiatric Disorders to be 5\%. The Prevalence of OCS in patients with Psychotic Disorders was found to be $9.9 \%$, in patients with Mood Disorders was found to be $6.6 \%$, in patients with Anxiety Disorders was found to be $2.3 \%$ and in patients with Substance Use Disorders was found to be 1.8\%. The most common Form of Obsession was Obsessive Thoughts (31.6\%), the most common Content was Inanimate-Impersonal (31.6\%) and the most common Compulsion was Washing (60\%). Mean YBOCS Score of all 19 patients was $9.95(\mathrm{SD}=5.1$, Median=9). 36.8\% patients had Subclinical Severity (0-7), 47.4\% patients had Mild Severity (8-15) and $15.8 \%$ patients had Moderate Severity (16-23). Psychotic \& mood disorders were further assessed for types \& severity of OCS. Though the prevalence of OCS in current study is less compared to previous studies, it still is significant. Thus various psychiatric disorders should be evaluated for presence of OCS.

KEYWORDS : Obsessive compulsive symptoms, prevalence, psychiatric disorders

\section{INTRODUCTION}

The clinical phenomenon of obsessive-compulsive symptoms (OCS) coexistent with various clinical disorders has intrigued clinicians for over a century. It was in the 19 th century that Westphal considered OC symptoms to be either a prodrome or an integral part of schizophrenia, as did Bleuler earlier in this century $(1,2)$. Both Kraeplin and Heilbronner believed that there was an intimate relationship between obsessions and manic depressive psychosis $(3,4)$. Lewisbelieved that obsessions in many instances were merely a manifestation of a universal psychic attribute, aggravated by the occurrence of some morbid state such as anxiety or depression (5).

\section{OCS in Schizophrenia \& psychotic disorders}

Previous studies which have used proper diagnostic interview [Diagnostic and Statistical Manual of Mental Disorders (DSM)-IV; Structured Clinical Interview for DSM-IV Axis I Disorders (SCID)] and Yale-Brown Obsessive-Compulsive Symptom checklist (YBOCS) have estimated the prevalence of OCS in Schizophrenia ranging between $14 \%$ and $26 \%(6,7)$. Previous meta analyses conclude that $12 \%$ of patients with schizophrenia also fulfil the criteria for obsessive-compulsive disorder (OCD) and that about 30\% report obsessive, distressing, intrusive thoughts and related compulsions $(8,9)$. Research done to evaluate the clinical impact of comorbid OCS in schizophrenia showed greater levels of hopelessness, lower quality of life, more social dysfunction and a higher degree of cognitive impairment. Consequently, patients with schizophrenia and comorbid OCS were reported to have a less favourable prognosis $(10,11,12)$.

\section{OCS in anxiety \& depressive disorders}

According to existing literature Obsessive compulsive symptoms (OCS) occur in $30 \%$ to $40 \%$ of patients with an anxiety or a depressive disorder (13). In depressive disorders, OCS are associated with poorer outcome (14). Research indicates presence of OCS in anxiety and depressive disorders in general is associated with severity and chronicity $(15,16)$.

\section{OCS in bipolar disorders}

There are many studies citing the presence of Mood Disorders like a depressive episode occurring secondary to OCD but studies on presence of Obsessive Compulsive Symptoms in Bipolar disorders are very few. Majority have studied OCS in context of OCD and not as an independent entity. Existing literature reports that 11 to $21 \%$ of persons with bipolar disorder experience comorbid OCD at some time during the course of their bipolar disorder (17). Most studies indicate that comorbid OCD exacerbates the symptoms of bipolar disorder leading to difficulty and challenges in treatment. It has been observed that Bipolar patients with comorbid OCD have more episodes of depression, higher rates of suicide, more chronic episodes and residual symptoms $(18,19)$

\section{OCS in substance use disorders}

A study done to find prevalence of OCS in alcoholic use patients found that the prevalence of probable OCD was high (20.4\%) (20) Compared with non-OCD alcoholics, probable OCD alcoholics more severe depressive symptoms and alcohol dependence, and more lifetime suicidal ideation, suicide plans and attempts This signifies the importance to actively investigate OCD symptoms in patients seeking treatment for substance use disorders and to indicate appropriate therapeutic interventions (21).

\section{AIMS \& OBJECTIVES:-}

1. To study the prevalence, types and severity of obsessive compulsive symptoms in psychiatric disorders.

\section{MATERIALS AND METHODS}

It was a cross sectional study carried out at psychiatry out patient department of a tertiary care institute. Sampling was done over period of 10 months. Minimum required sample size was calculated, which came out to be 246. Sample size was calculated based on following formula

$$
\text { Sample size }=\frac{\mathrm{Z}_{1-\alpha / 2}{ }^{2} \mathrm{p}(1-\mathrm{p})}{\mathrm{d}^{2}}
$$

$\mathrm{Z} 1-\mathrm{a} / 2=$ is standard normal variate (at $5 \%$ type 1 error $(P<0.05)$ it is 1.96 and at $1 \%$ type 1 error $(P<0.01)$ it is 2.58$)$. As in majority of studies $P$ values are considered significant below 0.05 hence 1.96 is used in formula. $\mathrm{p}=$ Expected proportion in population based on previous studies or pilot studies. Most of the studies have been done to find out prevalence of OCS in schizophrenia. So here we take it from a similar previous study, which found it to be $20 \%$ (23). $d=$ Absolute error or precision - The researcher wants to calculate this sample size with the precision/absolute error of $5 \%$ and at type 1 error of $5 \%$.

\section{INCLUSION CRITERIA}

1) Patients aged 18-60 years of age, attending psychiatry OPD, over a period of 10 months, having single Axis I psychiatric diagnosis 
as per DSM IV-TR

2) Patients willing to give consent

\section{EXCLUSION CRITERIA}

1) Patients diagnosed as Obsessive Compulsive Disorder according to DSM-IV-TR

2) Patients with history suggestive of organic brain pathology.

3) Patients having more than one diagnosis on Axis 1 of DSM-IVTR.

\section{TOOLS USED FOR THE STUDY}

1) Diagnostic and Statistical Manual of Mental Disorders, $4^{\text {th }}$ Edition, Text revision (DSM IV-TR) (24). It was used for diagnosis of obsessions \& compulsions.

2) Yale Brown Obsessive compulsive scale (YBOCS) (25)

The scale, which was designed by Wayne Goodman and his colleagues, is used extensively in research and clinical practice to both determine severity of OCD and to monitor improvement during treatment. This scale rates the severity of obsessive compulsive symptoms. The result can be interpreted as 0 to 7 , subclinical; 8 to 15 , mild; 16 to 23 , moderate; 24 to 31 , severe; and 32 to 40 , extreme severity.

\section{METHODOLOGY}

A total of 380 patients were included in the study after applying inclusion \& exclusion criteria. Semi-structured pro-forma was used to collect socio demographic data. Clinical diagnosis made as per criteria in Diagnostic \& Statistical Manual for Mental Disorders Fourth Edition, Text Revision (DSM IV- TR). YBOCS applied for assessing severity of obsessive compulsive symptoms. Data thus obtained was pooled and subjected to statistical analysis using the SPSS 16 software and Statistical tests of Frequencies, Independent $t$ Test and Pearson Chi-Square test applied

\section{RESULTS}
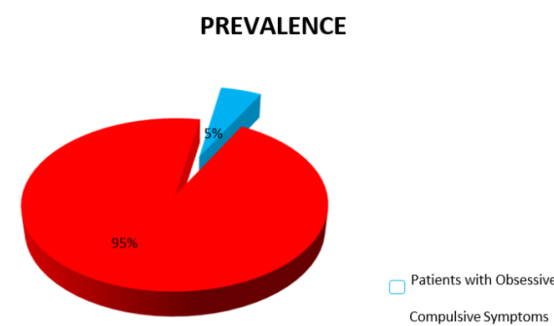

Diagram 1 : Frequency of OCS

FREQUENCY OF OCS

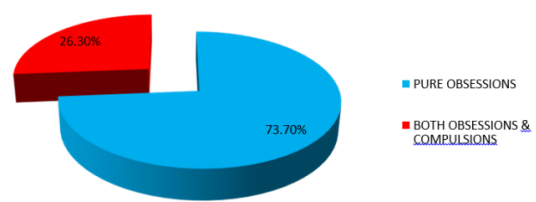

Diagram 2 : Frequency of obsessions \& compulsions in patients with OCS

\section{OBSESSIONS}

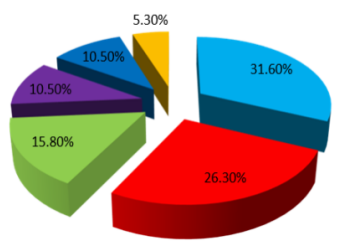

- NANMLATE-MMPRRONAL

- SEXTAT

- contamination

- SOMATIC

- MISCELLANEOUS

II AGGRESTION

Diagram 3 :

COMPULSIONS

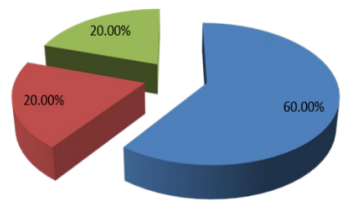

" WASHING

"AGGRESSION

$\because$ SEXUAL

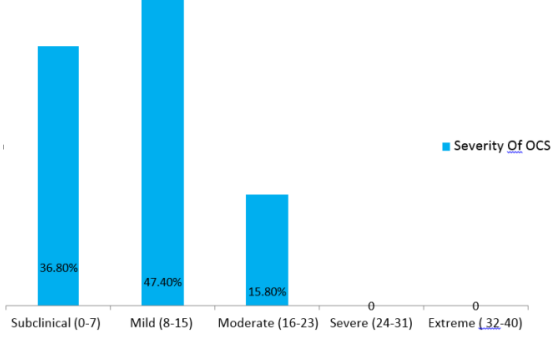

Diagram 5 : Severity of OCS

The severity of Obsessions and Compulsions was assessed using YBOCS Scale. On YBOCS, 7 patients (36.8\%) had Subclinical severity i.e. score of $0-7,9$ patients $(47.4 \%)$ had Mild severity i.e. score of 8-15 and 3 patients (15.8\%) had Moderate severity i.e. score of 1623. Mean YBOCS Score was $9.95(\mathrm{SD}=5.1$, Median=9).

TABLE 1 :SOCIODEMOGRAPHIC CHARECTERISTICS

\begin{tabular}{|c|c|c|c|c|c|c|}
\hline & \multicolumn{2}{|c|}{$\begin{array}{l}\text { TOTAL } \\
\text { PATIENTS } \\
\mathbf{N}=\mathbf{3 8 0}\end{array}$} & \multicolumn{2}{|c|}{$\begin{array}{l}\text { PATIENTS } \\
\text { WITH OCS } \\
\mathbf{N}=19\end{array}$} & \multicolumn{2}{|c|}{$\begin{array}{l}\text { PATIENTS } \\
\text { WITHOUT } \\
\text { OCS N=361 }\end{array}$} \\
\hline \multicolumn{7}{|l|}{ AGE : } \\
\hline MEAN & \multicolumn{2}{|c|}{34.53.} & \multicolumn{2}{|c|}{30.95} & \multicolumn{2}{|c|}{34.73} \\
\hline STANDARD & \multicolumn{2}{|c|}{10.547} & \multicolumn{2}{|c|}{9.330} & \multicolumn{2}{|c|}{10.575} \\
\hline \multicolumn{7}{|l|}{ DEVIATION } \\
\hline \multicolumn{7}{|l|}{ SEX : } \\
\hline MALE & 212 & $55.8 \%$ & 12 & $63.2 \%$ & 200 & $55.4 \%$ \\
\hline FEMALE & 168 & $44.2 \%$ & 7 & $36.8 \%$ & 161 & $44.6 \%$ \\
\hline $\begin{array}{l}\text { EDUCATION : } \\
\text { ILLITERATE } \\
\text { PRIMARY } \\
\text { SECONDARY } \\
\text { GRADUATE POST- } \\
\text { GRADUATE }\end{array}$ & $\begin{array}{l}45 \\
107 \\
157 \\
62 \\
9\end{array}$ & $\begin{array}{l}11.8 \% \\
28.2 \% \\
41.3 \% \\
16.3 \% \\
2.4 \%\end{array}$ & $\begin{array}{l}-1 \\
14 \\
4 \\
-\end{array}$ & $\begin{array}{l}-\quad 5.3 \% \\
73.7 \% \\
21.1 \% \\
-\end{array}$ & $\begin{array}{l}45 \\
106 \\
143 \\
58 \\
9\end{array}$ & $\begin{array}{l}12.5 \% \\
29.4 \% \\
39.6 \% \\
16.1 \% \\
2.5 \%\end{array}$ \\
\hline \multicolumn{7}{|l|}{ MARITAL STATUS: } \\
\hline SINGLE & 86 & $22.6 \%$ & 9 & $47.4 \%$ & 77 & $22.5 \%$ \\
\hline MARRIED & 275 & $77.4 \%$ & 10 & $52.6 \%$ & 265 & $73.4 \%$ \\
\hline WIDOWED/ & 19 & $5.0 \%$ & - & - & 19 & $5.3 \%$ \\
\hline \multicolumn{7}{|l|}{ SEPARATED } \\
\hline \multicolumn{7}{|l|}{ SOCIOECONOMIC } \\
\hline \multicolumn{7}{|l|}{ STATUS: } \\
\hline LOWER & 136 & $35.8 \%$ & 9 & $47.4 \%$ & 127 & $35.2 \%$ \\
\hline UPPER LOWER & 123 & $32.4 \%$ & 3 & $15.8 \%$ & 120 & $33.3 \%$ \\
\hline LOWER MIDDLE & 76 & $20 \%$ & 4 & $21.1 \%$ & 72 & $19.9 \%$ \\
\hline UPPER MIDDLE & 39 & $10.2 \%$ & 1 & $5.3 \%$ & 38 & $10.5 \%$ \\
\hline UPPER & 6 & $1.6 \%$ & 2 & $10.5 \%$ & 4 & $1.1 \%$ \\
\hline \multicolumn{7}{|l|}{ OCCUPATION: } \\
\hline SELF EMPLOYED & 37 & $9.7 \%$ & 4 & $21.1 \%$ & 33 & $9.1 \%$ \\
\hline $\begin{array}{l}\text { SERVICE } \\
\text { HOUSE-WIFE }\end{array}$ & $\begin{array}{l}154 \\
111 \\
\end{array}$ & $\begin{array}{l}40.6 \% \\
29.2 \% \\
\end{array}$ & $\begin{array}{l}7 \\
5\end{array}$ & $\begin{array}{l}36.8 \% \\
26.3 \% \\
\end{array}$ & $\begin{array}{l}147 \\
106 \\
\end{array}$ & $\begin{array}{l}40.7 \% \\
29.4 \% \\
\end{array}$ \\
\hline UNEMPLOYED & 78 & $20.5 \%$ & 3 & $15.8 \%$ & 75 & $20.8 \%$ \\
\hline \multicolumn{7}{|l|}{ TYPE OF FAMILY: } \\
\hline NUCLEAR & 192 & $50.5 \%$ & 8 & $42.1 \%$ & 184 & $51.0 \%$ \\
\hline JOINT & 188 & $49.5 \%$ & 11 & $57.9 \%$ & 177 & $49.0 \%$ \\
\hline
\end{tabular}

TABLE 2 : FREQUENCY OF OCS IN VARIOUS PSYCHIATRIC DIAGNOSIS

\begin{tabular}{|l|l|l|l|l|l|l|}
\hline & \multicolumn{2}{l|l}{$\begin{array}{l}\text { TOTAL } \\
\text { PATIENTS } \\
\text { N=380 }\end{array}$} & \multicolumn{2}{l|}{$\begin{array}{l}\text { PATIENTS } \\
\text { WITH OCS }\end{array}$} & \multicolumn{2}{l|}{$\begin{array}{l}\text { PATIENTS } \\
\text { WITHOUT } \\
\text { OCS N=361 }\end{array}$} \\
\hline $\begin{array}{l}\text { PSYCHOTIC } \\
\text { DISORDERS }\end{array}$ & 81 & $21.3 \%$ & 8 & $42.1 \%$ & 73 & $20.2 \%$ \\
\hline $\begin{array}{l}\text { MOOD } \\
\text { DISORDERS }\end{array}$ & 137 & $36.1 \%$ & 9 & $47.3 \%$ & 128 & $35.5 \%$ \\
\hline $\begin{array}{l}\text { ANXIETY } \\
\text { DISORDERS }\end{array}$ & 44 & $11.5 \%$ & 1 & $5.3 \%$ & 43 & $11.9 \%$ \\
\hline $\begin{array}{l}\text { SUBSTANCE } \\
\text { USE DISORDERS }\end{array}$ & 58 & $15.3 \%$ & 1 & $5.3 \%$ & 57 & $15.8 \%$ \\
\hline $\begin{array}{l}\text { OTHER } \\
\text { DISORDERS }\end{array}$ & 60 & $15.8 \%$ & - & - & 60 & $16.6 \%$ \\
\hline
\end{tabular}


Of the 19 patients with OCS, 8(42.1\%) patients had Psychotic Disorders, 9 (47.4\%) patients had Mood Disorders, 1(5.3\%) had Anxiety Disorder and 1(5.3\%) had Substance Use Disorders.

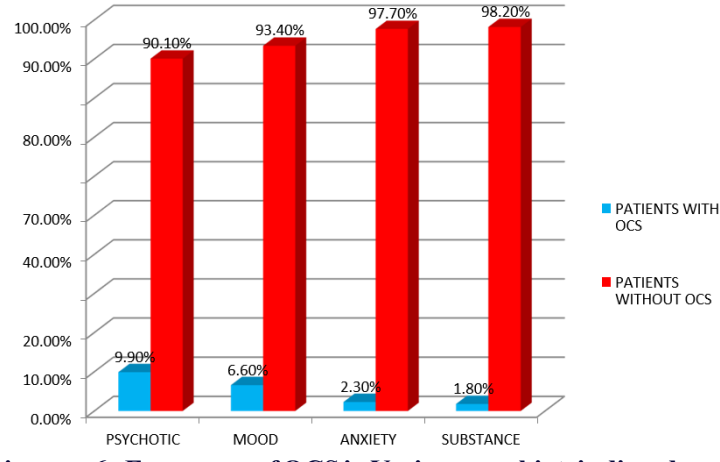

Diagram 6 : Frequency of OCS in Various psychiatric disorders

Patients with Psychotic Disorders and Patients with Mood Disorders were further assessed on these parameters: Types and Severity of OCS

\section{OCS AND PSYCHOTIC DISORDERS}

Of the 380 patients in this study 81 patients had a Psychotic Disorder and of these 81 patients, 8 patients had OCS. The Prevalence of OCS in patients with Psychotic Disorder was found to be $9.9 \%$.

Of the 8 patients Obsessions were found in all 8 patients and Compulsions were found in 4 patients. The most common Obsession was Sexual in $3(37.5 \%)$ patients followed by Contamination in 2 $(25 \%)$ patients. Somatic Obsessions, Aggressive Obsessions and Miscellaneous Obsessions were seen in $1(12.5 \%)$ patient each.

Of the 4 patients with Compulsions, the most common Compulsion was washing in $2(50 \%)$ patients followed by Sexual and Aggressive Compulsions in $1(25 \%)$ patient each. Of the 8 patients with OCS, 4 $(50 \%)$ patients had Subclinical severity, $2(25 \%)$ had Mild and Moderate severity each. The mean YBOCS Score was 11.25 ( $\mathrm{SD}=5.6$, median=9).

\section{PATIENTS WITH MOOD DISORDERS}

Of the 380 patients in this study, 137 patients had Mood Disorder and of these 137 patients, 9 patients had OCS. The Prevalence of OCS in patients with Mood Disorder was found to be $6.6 \%$.

Of the 9 patients with OCS, Obsessions were reported in all 9 patients and Compulsions were reported in none. The most common Obsession was Inanimate-Impersonal Obsessions seen in 4 (44.4\%) patients followed by Sexual Obsessions and Miscellaneous Obsessions seen in $2(22.2 \%)$ patients each and Somatic Obsession was seen in $1(11.1 \%)$ patient.

Of the 9 patients with OCS, 5 (55.6\%) patients had Subclinical severity and $4(44.4 \%)$ had Mild severity. The Mean YBOCS Score was 7.556 $(\mathrm{SD}=2.186$, Median $=8)$.

\section{DISCUSSION}

OCS IN SCHIZOPHRENIA \& PSYCHOTIC DISORDERS

In this study 81 patients had a Psychotic Disorder and of these 81 patients, 8 patients had OCS. The Prevalence of OCS in patients with Psychotic Disorder was found to be $9.9 \%$. Previous studies have found higher prevalence of OCS in schizophrenia. A study done in south india reported the prevalence of OCS in schizophrenia to be $28 \%$ (26), while a study conducted in north india found it to be $18 \%$ (27). Our study considered all psychotic spectrum disorders together while other studies studied prevalence in only schizophrenia. This might be the reason that the prevalence of OCS in our study was less compared to other studies.

Of the 8 patients Obsessions were found in all 8 patients and Compulsions were found in 4 patients. The most common Obsession was Sexual in $3(37.5 \%)$ patients followed by Contamination in 2 (25\%) patients. Somatic Obsessions, Aggressive Obsessions and Miscellaneous Obsessions were seen in $1(12.5 \%)$ patient each. Of the 4 patients with Compulsions, the most common Compulsion was washing in $2(50 \%)$ patients followed by Sexual and Aggressive Compulsions in $1(25 \%)$ patient each. A previous indian study had maximum patients suffering from aggressive obsessions(20\%) followed by miscellaneous(16\%) and Somatic obsessions(14\%) \& amongst the compulsive symptoms, cleaning was most common. followed by miscellaneous and checking (26). Other studies report most prevalent obsession to be fear of contamination and most prevalent compulsion to be cleaning $(27,28)$. This difference points to the necessity for such more studies to find out common obsessions \& compulsions in schizophrenia \& other psychotic disorders.

In our study of the 8 patients with OCS, $4(50 \%)$ patients had Subclinical severity, $2(25 \%)$ had Mild and Moderate severity each. The mean YBOCS Score was 11.25 ( $\mathrm{SD}=5.6$, median=9). Previous studies report the mean YBOCS score to be $18.24 \pm 7.20(27), 17.9 \pm$ 4.2 (29) and $22.95 \pm 9.52$ (28). Thus our study reported the mean YBOCS score to be less a s compared to other studies.

\section{OCS IN MOOD DISORDERS}

Of the 380 patients in this study, 137 patients had Mood Disorder and of these 137 patients, 9 patients had OCS. The Prevalence of OCS in patients with Mood Disorder was found to be $6.6 \%$. A recent meta analytic study found that the cross-sectional prevalence of OCD in Bipolar Disorder patients is $11.2 \%$ and the lifetime prevalence rate was $10.9 \%$, suggesting that in Bipolar Disorder patients OCD symptomatology is chronic rather than episodic (30) while as per previous meta-analytic studies, comorbid OCD prevalence in Bipolar Disorder varied from $7.1 \%$ (31) to $21.7 \%$ (32)

Also literature reports prevalence OCS in $23.6 \%$ of the total sample of those with current anxiety \& depressive disorders. Research indicates that OCS were associated with severity of the disorder, predicted relapse in those with remitted anxiety and/or depressive disorders (33). This impact of OCS on severity and course of mood disorders highlights the significance of evaluating for OCS in mood disorders.

Of the 9 patients with OCS in mood didorders, Obsessions were reported in all 9 patients and Compulsions were reported in none. The most common Obsession was Inanimate-Impersonal Obsessions seen in $4(44.4 \%)$ patients followed by Sexual Obsessions and Miscellaneous Obsessions seen in $2(22.2 \%)$ patients each and Somatic Obsession was seen in $1(11.1 \%)$ patient. In a previous study done to explore Obsessive compulsive disorder in Bipolar affective disorder patients, it was found that among the obsessive symptoms, contamination obsession $(69.2 \%)$ was the most prevalent type, followed by aggressive obsession $(57.7 \%)$, somatic obsession (34.6\%), obsession for hoarding (30.8\%), and obsession for symmetry (30.8\%) \& among compulsions, checking was the most common type, occurring in $80.8 \%$ of the subjects, followed by cleaning $(57.7 \%)$ and hoarding $(42.3 \%)$.

In this study, of the 9 patients with OCS in mood disorders, 5 (55.6\%) patients had Subclinical severity and $4(44.4 \%)$ had Mild severity. The Mean YBOCS Score was 7.556 (SD=2.186, Median=8).

\section{OCS IN ANXIETY DISORDERS \& SUBSTANCE USE DISORDERS}

Our study found the prevalence of OCS in anxiety disorders to be $2.3 \%$. There is scarcity in literature regarding OCS in anxiety disorders. One study reports the prevalence of OCS in anxiety disorders to be $30 \%$. The reason of low prevalence in our study might be due to less sample size. In this study the prevalence of OCS in substance use disorders was found to be $1.72 \%$. In a recent study, onemonth prevalence of probable OCD among the alcoholics under outpatient treatment was $20.4 \%$

\section{CONCLUSION}

Our study reports the prevalence rates of obsessive compulsive symptoms in various psychiatric disorders $-9.9 \%$ in psychotic disorders, $6.6 \%$ in mood disorders, $2.3 \%$ in anxiety disorders \& $1.72 \%$ in substance use disorders . Severity of OCS was mostly in subclinical to mild range. Though the prevalence is less compared to previous studies, it still depicts a significant prevalence rate. There have been studies in the past signifying the impact of OCS on severity and course of various psychiatric disorders. Future studies need to be carried out to find the prevalence, clinical correlates of OCS in psychiatric disorders and impact of OCS on course of psychiatric disorders.

\section{REFERENCES}

1) Westphal K. 1878. Uber Zwangsvorstellungen. Archiv fur Psychiatr und Nervenkr ,8 ,734-50. 
2) Kraepelin, E. (1919). Dementia praecox and paraphrenia. Livingstone.

3) Kraepelin, E. (1904). Lectures on clinical psychiatry (T. Johnstone, Trans.). New York: William Wood.

4) Heilbronner, K. (1912). Zwangsvorstellung und Psychose. Zeitschrift für die gesamte Neurologie und Psychiatrie, 9(1), 301-347.

5) Lewis, A. (1936). Problems of obsessional illness

6) Poyurovsky, M., \& Koran, L. M. (2005). Obsessive-compulsive disorder (OCD) with schizotypy vs. schizophrenia with OCD: diagnostic dilemmas and therapeutic implications. Journal of Psychiatric Research, 39(4), 399-408.

7) Poyurovsky, M., Faragian, S., Pashinian, A., Heidrach, L., Fuchs, C., Weizman, R., \& Koran, L. (2008). Clinical characteristics of schizotypal-related obsessive-compulsive disorder. Psychiatry research, 159(1-2), 254-258.

8) Swets, M., Dekker, J., van Emmerik-van Oortmerssen, K., Smid, G. E., Smit, F., de Haan, L., \& Schoevers, R. A. (2014). The obsessive compulsive spectrum in schizophrenia, a meta-analysis and meta-regression exploring prevalence rates. Schizophrenia Research, 152(2-3), 458-468.

9) Achim, A. M., Maziade, M., Raymond, É, Olivier, D., Mérette, C., \& Roy, M. A. (2011) How prevalent are anxiety disorders in schizophrenia? A meta-analysis and critical How prevalent are anxiety disorders in schizophrenia? A meta-analysis

10) De Haan, L., Sterk, B., \& van der Valk, R. (2013). Presence of obsessive compulsive symptoms in first-episode schizophrenia or related disorders is associated with subjective well-being and quality of life. Early intervention in psychiatry, 7(3), 285-290.

11) Varlakova, Y., Patel, D. D., Mukhopadhaya, K., Laws, K. R., David, E., Sukwinder, K., \& Fineberg, N. A. (2015). The neurocognitive and behavioural impact of comorbid obsessive-compulsive syndrome in schizophrenia. In Obsessive-Compulsive Symptoms in Schizophrenia (pp. 91-114). Springer, Cham

12) Guillem, F., Satterthwaite, J., Pampoulova, T., \& Stip, E. (2009). Relationship between psychotic and obsessive compulsive symptoms in schizophrenia. Schizophrenia Research, 115(2-3), 358-362

13) Fullana, M. A., Mataix-Cols, D., Caspi, A., Harrington, H., Grisham, J. R., Moffitt, T. E., \& Poulton, R. (2009). Obsessions and compulsions in the community: prevalence, interference, help-seeking, developmental stability, and co-occurring psychiatric conditions. American Journal of Psychiatry, 166(3), 329-336.

14) Baer, L., Trivedi, M. H., Huz, I., Rush, A. J., Wisniewski, S. R., \& Fava, M. (2015). Prevalence and impact of obsessive-compulsive symptoms in depression: a STAR* D report. The Journal of clinical psychiatry, 76(12), 1668-1674.

15) Fichter, M. M., Quadflieg, N., Fischer, U. C., \& Kohlboeck, G. (2010). Twenty-five-year course and outcome in anxiety and depression in the Upper Bavarian Longitudinal Community Study. Acta Psychiatrica Scandinavica, 122(1), 75-85.

16) Hofmeijer-Sevink, M. K., van Oppen, P., van Megen, H. J., Batelaan, N. M., Cath, D. C., van der Wee, N. J., ... \& van Balkom, A. J. (2013). Clinical relevance of comorbidity in obsessive compulsive disorder: the Netherlands OCD Association study. Journal of affective disorders, $150(3), 847-854$

17) Amerio, A., Odone, A., Marchesi, C., \& Ghaemi, S. N. (2014). Treatment of comorbid bipolar disorder and obsessive-compulsive disorder: A systematic review. Journal of affective disorders, 166, 258-263.

18) Kazhungil, F., Cholakottil, A., Kattukulathil, S., Kottelassal, A., \& Vazhakalayil, R. (2017). Clinical and familial profile of bipolar disorder with and without obsessivecompulsive disorder: an Indian study. Trends in psychiatry and psychotherapy, 39(4), $270-275$.

19) Koyuncu, A., Tükel, R., Özyıldırım, İ., Meteris, H., \& Yazıcı, O. (2010). Impact of obsessive-compulsive disorder comorbidity on the sociodemographic and clinical features of patients with bipolar disorder. Comprehensive psychiatry, 51(3), 293-297.

20) Campos, L. M., Yoshimi, N. T., Simão, M. O., Torresan, R. C., \& Torres, A. R. (2015). Obsessive-compulsive symptoms among alcoholics in outpatient treatment: Prevalence, severity and correlates. Psychiatry Research, 229(1-2), 401-409.

21) Wahl, K., Kordon, A., Kuelz, K. A., Voderholzer, U., Hohagen, F., \& Zurowski, B. (2010). Obsessive-Compulsive Disorder (OCD) is still an unrecognised disorder: A study on the recognition of OCD in psychiatric outpatients. European Psychiatry, 25(7), 374-377.

22) Charan, J., \& Biswas, T. (2013). How to calculate sample size for different study designs in medical research?. Indian journal of psychological medicine, 35(2), 121.

23) Bottas, A., Cooke, R. G., \& Richter, M. A. (2005). Comorbidity and pathophysiology of obsessive-compulsive disorder in schizophrenia: Is there evidence for a schizoobsessive-compulsive disorder in schizophrenia: Is there evidence for a schizo-
obsessive subtype of schizophrenia?. Journal of Psychiatry and Neuroscience, 30(3), obsessive subtype of schizophrenia?. Journal of Psychiatry and Neuroscience, 30(3),
187 .

24) Diagnostic and statistical manual of mental disorders: DSM-IV-TR. 4th ed., text revision. (2000). Washington, DC:APA

25) Goodman, W. K., Price, L. H., Rasmussen, S. A., Mazure, C., Delgado, P., Heninger, G. R., \& Charney, D. S. (1989). The yale-brown obsessive compulsive scale: II. Validity. Archives of general psychiatry, 46(11), 1012-1016.

26) Mulky, P., Raghavan, D. V., Maheshwari, S., Kannan, P., \& Jeyaprakash, R. (2016). Obsessive-Compulsive symptoms in patients with Schizophrenia attending tertiary care centre in South India. Stanley Medical J, 2(4), 2-7.

27) Singh, A., Beniwal, R. P., Bhatia, T., \& Deshpande, S. N. (2019). Prevalence and clinical correlations of obsessive-compulsive symptoms in schizophrenia. Asian journal of psychiatry, 39, 48-52

28) Devi, S., Rao, N. P., Badamath, S., Chandrashekhar, C. R., \& Reddy, Y. J. (2015). Prevalence and clinical correlates of obsessive-compulsive disorder in schizophrenia. Comprehensive psychiatry, $56,141-148$

29) Hosseini, S. H., Zarghami, M., Moudi, S., \& Mohammadpour, A. R. (2012). Frequency and severity of obsessive-compulsive symptoms/disorders, violence and suicidal in schizophrenic patients. Iranian Red Crescent Medical Journal, 14(6), 345.

30) Ferentinos, P., Preti, A., Veroniki, A. A.,Pitsalidis, K. G., Theofilidis, A. T., Antoniou, A., \& Fountoulakis, K. N. (2020). Comorbidity of obsessive-compulsive disorder in bipolar spectrum disorders: systematic review and meta-analysis of its prevalence. Journal of Affective Disorders, 263, 193-208.

31) Pavlova, B., Perlis, R. H., Mantere, O., Sellgren, C. M., Isometsä, E., Mitchell, P. B., ... \& Uher, R. (2017). Prevalence of current anxiety disorders in people with bipolar disorder during euthymia: a meta-analysis. Psychological medicine, 47(6), 1107

32) Amerio, A., Stubbs, B., Odone, A., Tonna, M., Marchesi, C., \& Ghaemi, S. N. (2016). Bipolar I and II disorders; a systematic review and Meta-analysis on differences in comorbid obsessive-compulsive disorder. Iranian journal of psychiatry and behavioral sciences, 10(3).

33) Hofmeijer-Sevink, M. K., Batelaan, N. M. van Megen, H. J., van den Hout, M. A., Penninx, B. W., van Balkom, A. J., \& Cath, D. C. (2018). Presence and predictive value Penninx, B. W., van Balkom, A. J., \& Cath, D. C. (2018). Presence and predictive value
of obsessive-compulsive symptoms in anxiety and depressive disorders. The Canadian of obsessive-compulsive symptoms
Journal of Psychiatry, 63(2), 85-93.

34) Campos, L. M., Yoshimi, N. T., Simão, M. O., Torresan, R. C., \& Torres, A. R. (2015). Obsessive-compulsive symptoms among alcoholics in outpatient treatment: Prevalence, severity and correlates. Psychiatry Research, 229(1-2), 401-409. 